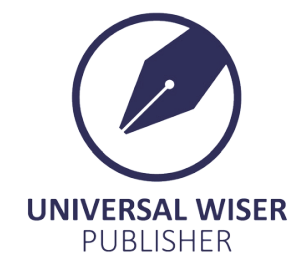

\title{
Investigation of Complex Formation Process of Copper with Macromolecular Organic Substances, Isolated from Natural Waters
}

\author{
T.Makharadze*, G.Makharadze \\ Department of Chemistry, Ivane Javakhishvili Tbilisi State University, Georgian \\ Email: makharadze_tako@yahoo.com
}

\begin{abstract}
Natural macromolecular organic substances-fulvic acids take an active part in complex formation processes and stipulate migration forms of heavy metals in natural waters The calculation of the migration forms of heavy metals is one of the problematic issue of the contemporary chemistry, which couldn't be solved without using the conditional stability constants of fulvate complexes. In spite of researches, experimental data on stability constants of complex compounds of fulvic acids with heavy metals ( among them copper) are heterogeneous and they differ in several lines from each other. One of the reason of such condition is ignoring an average molecular weight of the associates of fulvic acids, which finally causes the wrong results. Complex formation process between copper (II) and fulvic acids was studied by the solubility method at $\mathrm{pH}=9.0 . \mathrm{Cu}(\mathrm{OH})_{2}$ suspension was used as a solid phase. Fulvic acids were isolated from Paravani lake by the adsorption -chromatographic method. In this article is shown that, during complex formation process every $1 / 4$ part of an associate of fulvic acids $(\mathrm{Mw}=7610)$, inculcates into copper's inner coordination sphere as an integral ligand, so it may assume, that the average molecular weight of the associate of fulvic acids which takes part in complex formation process equals to 1903. This part of the associate of fulvic acids was conventionally called an "active associate". The average molecular weight of the "active associate" was used for determination the composition of copper fulvate complex, the concentration of free ligand and stability constant, which equals to $2.25 \times 10^{7}$
\end{abstract}

Keywords: fulvic acids, copper, stability constant, average molecular weight

\section{Introduction}

Fulvic acids (FA) are one of the first macromolecular organic substances, which were discovered in natural waters. Originally the term "fulvic acids" was used for all natural organic substances which were solved in acid and which remained after the acidification of soil alkaline extracts.

At present time, this term means those substances which are solved in acid and their isolation from other organic substances can be done during the fractionating by using the activated charcoal or other sorbents.

FA have functional groups and that's why they take an active part in complex formation and sorption processes, proceeding in natural waters, suspended substances, bottom sediments and soils. They form stable complexes with heavy metals, pesticides and radionuclides. In certain conditions, they contribute in formation of mutagen and toxic metal organic compounds, stipulate migration forms of heavy metals and determine chemical-ecological condition of natural objects.

The macromolecules of fulvic acids are rich in aromatic units, aliphatic chains and functional groups and reveal flexibility and high sensitivity to chemical agents ${ }^{[1-14]}$.

In spite of researches, experimental data on stability constants ( $\beta$ ) of complex compounds of FA with copper (II) are heterogeneous and they differ in several lines from each other ${ }^{[3],[5],[6],[11],[12]}$.

This condition is mainly stipulated by the ignoring the average molecular weight (Mw) of the associates of FA, which value in its turn depends on value of $\mathrm{pH}$ and finally causes the wrong result.

Therefore, it's difficult to investigate complex formation processes, taking place in natural waters, identify migration forms of copper and evaluate and assess chemical-ecological condition of natural waters.

Objective of the work was to obtain pure samples of FA, to investigate complex formation process between the pure samples of FA, isolated from natural water and $\mathrm{Cu}(\mathrm{II})$ and to calculate $\beta$ of copper fulvate complex. Complex formation process was studied at $\mathrm{pH}=9.0$ by the solubility method. $\mathrm{Cu}(\mathrm{OH})_{2}$ suspension was used as a solid phase.

Copyright (C)2020 T.Makharadze, et al.

DOI: https://doi.org/10.37256/ocp.112020101

This is an open-access article distributed under a CC BY license

(Creative Commons Attribution 4.0 International License)

https://creativecommons.org/licenses/by/4.0/ 


\section{Materials and methods}

For obtaining pure samples of FA, after filtration through membrane filters $(0.45 \mu \mathrm{m}$ pore size $)$, the water of Paravani lake was concentrated by the frozen method. The concentrated water samples were acidified with $6 \mathrm{M} \mathrm{HCl}$ to $\mathrm{pH} 2$ and was put for 2 hours on water bath at 60 for coagulation of humin acids. Then the solution was centrifuged for 10 min at $8000 \mathrm{rpm}$ (Centrifuge T-23). For the isolation of FA from centrifugate was used the adsorption-chromatographic method. Charcoal was used as a sorbent. Desorption of amino acids and carbohydrates was performed by means of $0.1 \mathrm{M} \mathrm{HCl}$. For desorption of polyphenols was used $90 \%$ acetone water solution. The eluation of the fraction of FA was performed with $0.1 \mathrm{~N} \mathrm{NaOH}$ solution ${ }^{[10],[15]}$. Obtained alkalic solution of FA, for the purification was passed through a cation-exchanger (KU-2-8). For determination the concentration of FA in obtained solution was used gravimetric method, the part of the solution was dried under vacuum until the constant weight was obtained. Then, model solutions of FA were prepared. The solution of fulvate complexes was obtained by the solubility method. $0.1 \mathrm{ml}$ suspension of copper hydroxide and increasing quantity of standard solution of FA were placed in $15 \mathrm{ml}$ capacity fluoroplastic cylinders. pH9.0,ionic strength $\mu=0.01$ $\left(\mathrm{KNO}_{3}\right), \mathrm{v}=10 \mathrm{ml}$. The concentration of hydrogen ions was regulated by the addition of $0.01 \mathrm{M} \mathrm{HNO}_{3}$ acid or $0.01 \mathrm{M}$ $\mathrm{NaOH}(\mathrm{pH}$ meter $\mathrm{pH}$ 2006). Then, it was stirred in a mechanical mixer for 100 hours, until the balance was achieved and then suspension was filtered through the membrane filters ( $0.45 \mu \mathrm{m}$ pore size). In filtrates, the concentration of copper was measured by atomic absorption spectrophotometer (Perkin elmer 200).

\section{Results and discussion}

FA form associates in water solutions. It was established, that in the interval $\mathrm{pH} 4-11$, there is a line dependence between $\mathrm{Mw}$ and the value of $\mathrm{pH}$, which is expressed in the following way : $\mathrm{Mw}=1350 \mathrm{pH}-4540^{[10]}$. Molar concentrations of fulvic acids at $\mathrm{pH}=9.0(\mathrm{Mw}=7610)$ could be calculated.

The data show, that in line with the increase of concentration of FA in the solution, the concentration of copper increases for several times as well due to formation of fulvate complex.

In complex formation process the participation of carboxyl or phenol groups of fulvic acids depends on different factors, first of all on the meaning of $\mathrm{pH}$ and the nature of metal ${ }^{[1]}$.

If it is not be taken into account charges of ions, the reaction of formation of copper fulvate complexes, could be written in the following way $\mathrm{Cu}(\mathrm{II})_{\text {free }}+\mathrm{mFA}_{\text {total }}=\mathrm{CuFA}_{\mathrm{m}}$

$$
\beta=\left[\mathrm{CuFA}_{\mathrm{m}}\right] /\left(\left[\mathrm{Cu}(\mathrm{II})_{\text {free }}\right]\left[\mathrm{FA}_{\text {total }}\right]^{\mathrm{m}}\right)
$$

In balanced solutions, correlation $\left[\mathrm{Cu}(\mathrm{II})_{\text {total }}\right]:\left[\mathrm{FA}_{\text {total }}\right]$ on average equals to $1: 0,25$. This means, that during the complex formation process, the associate of $\mathrm{FA}$, which $\mathrm{Mw}$ at $\mathrm{pH}=9$ equals to 7610 , divides and every $1 / 4$ part of this associate inculcates into copper's (II) inner coordination sphere, as an integral ligand. So it may assume, that Mw of the associate of FA which takes part in complex formation process equals to 1903. This part of the associate of FA was conventionally called an "active associate". The meaning of $\mathrm{Mw}$ of the "active associate" of fulvic acid ( $\mathrm{Mw}=1903$ ) was used for determination the composition of copper fulvate complexes, the concentration of free ligand $\left(\left[\mathrm{FA}_{\text {free }}\right]\right)$ and $\beta^{[16]}$. It should be noted, that in case of using $\mathrm{Mw}$ of the associate (7610), it will be impossible to calculate $\left[\mathrm{FA}_{\text {free }}\right]$. The calculation of $\left[\mathrm{FA}_{\text {free }}\right]$ is impossible. Without it, it's impossible to calculate $\beta$ of copper fulvate complex .

In solution, the concentration of fulvate complex equals to the difference between total and free concentrations of copper (II) received after formation the complex:

$$
\begin{aligned}
& {\left[\mathrm{CuFA}_{\mathrm{m}}\right]=\left[\mathrm{Cu}(\mathrm{II})_{\text {total }}\right]-\left[\mathrm{Cu}(\mathrm{II})_{\text {free }}\right]} \\
& \beta=\left(\left[\mathrm{Cu}(\mathrm{II})_{\text {total }}\right]-\left[\mathrm{Cu}(\mathrm{II})_{\text {free }}\right]\right) /\left(\left[\mathrm{Cu}(\mathrm{II})_{\text {free }}\right]\left[\mathrm{FA}_{\text {total }}\right]^{\mathrm{m}}\right)
\end{aligned}
$$

From (4) equation

$$
\beta\left[\mathrm{Cu}(\mathrm{II})_{\text {free }}\right]=\left(\left[\mathrm{Cu}(\mathrm{II})_{\text {total }}\right]-\left[\mathrm{Cu}(\mathrm{II})_{\text {free }}\right]\right) /\left[\mathrm{FA}_{\text {total }}\right]^{\mathrm{m}}
$$

At the fixed $\mathrm{pH}$, the left part of the equation is a permanent value and was marked it as

$$
\mathrm{K}^{\prime}=\left(\left[\mathrm{Cu}(\mathrm{II})_{\text {total }}\right]-\left[\mathrm{Cu}(\mathrm{II})_{\text {free }}\right] / \text { [FA }_{\text {total }}\right]^{\mathrm{m}}
$$


The logarithm of this equation is:

$$
\log \mathrm{K}^{\prime}=\log \left(\left[\mathrm{Cu}(\mathrm{II})_{\text {total }}\right]-\left[\mathrm{Cu}(\mathrm{II})_{\text {free }}\right]\right)-\mathrm{mlog}\left[\mathrm{FA}_{\text {total }}\right]
$$

The numeral value $(\mathrm{m})$ of the stoichiometric coefficient or the number of ligands in the inner coordination sphere of complex equals to tangent of tilt angle of straight line built in coordinates

$$
\log \left(\left[\mathrm{Cu}(\mathrm{II})_{\text {total }}\right]-\left[\mathrm{Cu}(\mathrm{II})_{\text {free }}\right]\right)-\mathrm{mlog}\left[\mathrm{FA}_{\text {total }}\right]
$$

To calculate the exact value of tangent tilt angle of straight line, for this purpose was used the least square method

After the calculation, was obtained the numeral value of $\mathrm{m}(\mathrm{Mw}(\mathrm{FA})=7610)$ and $\mathrm{m}(\mathrm{Mw}(\mathrm{FA})=1903)$, which equal to 0.97 and 0.94. (table 1-4).

Table 1. The dependence of the solubility of copper hydroxide on the concentration of fulvic acids and the necessary data for the identification the composition of copper fulvate complexes

\begin{tabular}{|c|c|c|c|c|c|}
\hline [FAtotal] & $\begin{array}{c}\mathrm{Mol} / \mathrm{L} \\
{[\mathrm{Cu} \text { total }]}\end{array}$ & [CuFAm] & $\begin{array}{c}\text { [Cu(II)total]1: } \\
\text { [FAtotal] }\end{array}$ & $\lg$ [FAtota] & $\lg [\mathrm{CuFAm}]$ \\
\hline $1,15 \times 10^{-5}$ & $4,79 \times 10^{-5}$ & $4,60 \times 10^{-5}$ & $1: 0,24$ & $-4,9393$ & $-4,3372$ \\
\hline $1,72 \times 10^{-5}$ & $6,89 \times 10^{-5}$ & $6,70 \times 10^{-5}$ & $1: 0,25$ & $-4,7645$ & $-4,1739$ \\
\hline $2,30 \times 10^{-5}$ & $9,22 \times 10^{-5}$ & $9,03 \times 10^{-5}$ & $1: 0,25$ & $-4,6383$ & $-4,0443$ \\
\hline $2,87 \times 10^{-5}$ & $11,61 \times 10^{-5}$ & $11,42 \times 10^{-5}$ & $1: 0,25$ & $-4,5421$ & $-3,9423$ \\
\hline $3,45 \times 10^{-5}$ & $13,67 \times 10^{-5}$ & $13,48 \times 10^{-5}$ & $1: 0,25$ & $-4,4622$ & $-3,8703$ \\
\hline $4,02 \times 10^{-5}$ & $16,01 \times 10^{-5}$ & $15,82 \times 10^{-5}$ & $1: 0,25$ & $-4,3958$ & $-3,8008$ \\
\hline $4,60 \times 10^{-5}$ & $17,34 \times 10^{-5}$ & $17,15 \times 10^{-5}$ & $1: 0,26$ & $-4,3372$ & $-3,7657$ \\
\hline
\end{tabular}

pH=9.0; $\mathrm{Mw}(\mathrm{FA})=7610 ;\left[\mathrm{CuFA}_{\mathrm{m}}\right]=\left[\mathrm{Cu}(\mathrm{II})_{\text {total }}\right]_{-}\left[\mathrm{Cu}(\mathrm{II})_{\text {free }}\right] ;\left[\mathrm{Cu}_{\text {free }}\right]=1 ; 92 \times 10^{-6} \mathrm{~mol} / \mathrm{L}$

Table 2. The calculation of the composition of copper fulvate fomplex by the Least Square Method

\begin{tabular}{cccc}
$\mathbf{M w}(\mathbf{F A})=\mathbf{7 6 1 0} ; \mathbf{p H}=\mathbf{9 . 0} ; \mathbf{X i}=\log \left[\mathbf{F} \mathbf{A}_{\text {total }}\right] ; \mathbf{Y i}=\log \left[\mathbf{C u} \mathbf{F} \mathbf{A}_{\mathbf{m}}\right]$ \\
\hline $\mathbf{X i}$ & $\mathbf{Y i}$ & $\mathbf{X i Y i}$ & $\mathbf{X i}^{2}$ \\
\hline$-4,9393$ & $-4,3372$ & 21,4227 & 24,3967 \\
$-4,7645$ & $-4,1739$ & 19,8865 & 22,7005 \\
$-4,6383$ & $-4,0443$ & 18,7587 & 21,5138 \\
$-4,5421$ & $-3,9423$ & 17,9063 & 20,6306 \\
$-4,4622$ & $-3,8703$ & 17,2700 & 19,9112 \\
$-4,3958$ & $-3,8008$ & 16,7076 & 19,3230 \\
$-4,3372$ & $-3,7657$ & 16,3326 & 18,8113 \\
\hline
\end{tabular}

$\sum X i=-32,0794 ;\left(\sum X i\right)^{2}=1029,0879 ; \sum Y i=-27,9345 ; \sum X i^{2}=147,2871 ; \sum X i Y=128,2844$

$\mathrm{m}=\operatorname{tga}=\left(\mathrm{nSx}_{\mathbf{i}} \mathrm{y}_{\mathbf{i}}-\mathrm{Sx}_{\mathbf{i}} \mathrm{Sy}_{\mathbf{i}}\right) /\left(\mathrm{nSx}_{\mathbf{i}}{ }^{2}-\left(\mathrm{Sx}_{\mathbf{i}}\right)^{2}\right)=0.97$

Table 3. The solubility methoWd, the necessary data for the calculation of copper fulvate fomplex by the Least Square Method

\begin{tabular}{|c|c|c|c|c|}
\hline$\left[\mathbf{F A}_{\text {total }}\right]$ & $\begin{array}{c}\mathrm{Mol} / \mathrm{L} \\
{\left[\mathrm{Cu}_{\text {total }}\right]}\end{array}$ & {$\left[\mathbf{C u F A}_{\mathrm{m}}\right]$} & $\lg \left[\mathbf{F} A_{\text {tota }}\right]$ & $\lg \left[\mathbf{C u F A} A_{m}\right]$ \\
\hline $4,61 \times 10^{-5}$ & $4,79 \times 10^{-5}$ & $4,60 \times 10^{-5}$ & $-4,3363$ & $-4,3372$ \\
\hline $6,91 \times 10^{-5}$ & $6,89 \times 10^{-5}$ & $6,70 \times 10^{-5}$ & $-4,1605$ & $-4,1739$ \\
\hline $9,22 \times 10^{-5}$ & $9,22 \times 10^{-5}$ & $9,03 \times 10^{-5}$ & $-4,0353$ & $-4,0443$ \\
\hline $11,52 \times 10^{-5}$ & $11,61 \times 10^{-5}$ & $11,42 \times 10^{-5}$ & $-3,9385$ & $-3,9423$ \\
\hline $13,83 \times 10^{-5}$ & $13,67 \times 10^{-5}$ & $13,48 \times 10^{-5}$ & $-3,8592$ & $-3,8703$ \\
\hline $16,13 \times 10^{-5}$ & $16,01 \times 10^{-5}$ & $15,82 \times 10^{-5}$ & $-3,7924$ & $-3,8008$ \\
\hline $18,48 \times 10^{-5}$ & $17,34 \times 10^{-5}$ & $17,15 \times 10^{-5}$ & $-3,7333$ & $-3,7657$ \\
\hline
\end{tabular}
$\mathrm{pH}=9.0 ; \mathrm{Mw}(\mathrm{FA})=1903 ;\left[\mathrm{CuFA}_{\mathrm{m}}\right]=\left[\mathrm{Cu}(\mathrm{II})_{\text {total }}\right]_{-}\left[\mathrm{Cu}(\mathrm{II})_{\text {free }}\right] ;\left[\mathrm{Cu}_{\text {free }}\right]=1 ; 92 \times 10^{-6} \mathrm{~mol} / \mathrm{L}$

Table 4. The Calculation of the Composition Copper Fulvate Complex by the Least Square Method $\operatorname{Mw}(\mathbf{F A})=1903 ; \mathrm{pH}=9.0 ; \mathrm{Xi}=\log \left[\mathbf{F A} A_{\text {total }}\right] ; \mathrm{Yi}=\log [\mathrm{CuFA}$ m $]$

\begin{tabular}{cccc}
\hline $\mathrm{Xi}$ & $\mathrm{Yi}$ & $\mathrm{XiYi}$ & $\mathrm{Xi}^{2}$ \\
\hline$-4,1605$ & $-4,1739$ & 17,3655 & 17,3098 \\
$-4,0353$ & $-4,0443$ & 16,3199 & 16,2836 \\
$-3,9385$ & $-3,9423$ & 15,5267 & 15,5118
\end{tabular}




\begin{tabular}{cccc}
$-3,8592$ & $-3,8703$ & 14,9363 & 14,8934 \\
$-3,7924$ & $-3,8008$ & 14,4141 & 14,3823 \\
$-3,7333$ & $-3,7657$ & 14,0585 & 13,9375 \\
\hline $\mathbf{m}=\mathbf{t g} \mathbf{a}=\left(\mathbf{n} \mathbf{S x}_{\mathbf{i}} \mathbf{y}_{\mathbf{i}} \mathbf{-} \mathbf{S x}_{\mathbf{i}} \mathbf{S} \mathbf{y}_{\mathbf{i}}\right) /\left(\mathbf{n}^{\mathbf{S x}} \mathbf{x}_{\mathbf{i}}{ }^{2}-\left(\mathbf{S x}_{\mathbf{i}}\right)^{\mathbf{2}}\right)=\mathbf{0 . 9 4}$
\end{tabular}

So in $\mathrm{Cu}(\mathrm{OH})_{2}$ (solid) $-\mathrm{Cu}(\mathrm{II})$ (solution) $-\mathrm{FA}-\mathrm{H}_{2} \mathrm{O}$ system at $\mathrm{pH}=9.0$, dominates copper fulvate complex , with the structure $1: 1$

For the calculation of $\beta$ of copper fulvate at $\mathrm{pH}=9.0$ was used Leden function $\mathrm{F}(\mathrm{L})^{[17]}$. The necessary data, for calculation the conditional stability constants of copper fulvate complex are given in table 5-6.

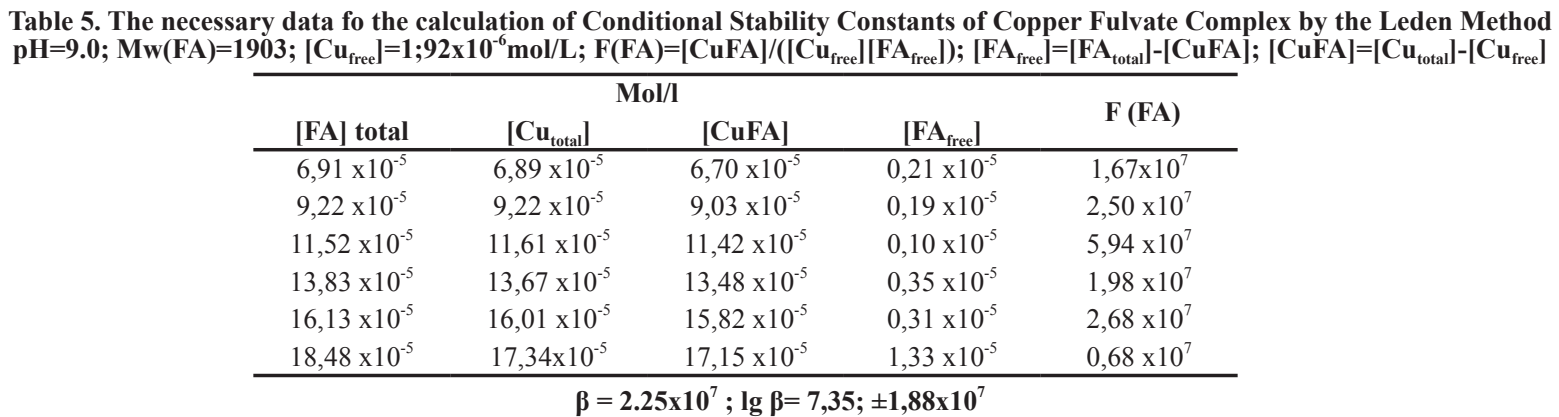

Table 6. The calculation of conditional stability constant of copper fulvate complex by the least Square Method $\mathrm{Mw}(\mathrm{FA})=1903 ; \mathrm{pH}=9.0 ; \mathrm{Xi}=\left[\mathbf{F A} \mathbf{f r e e}_{\text {fre }}\right] \mathrm{Yi}=\mathbf{F}(\mathbf{F A})$

\begin{tabular}{cccc}
\hline $\mathbf{X i}$ & $\mathbf{Y i}$ & $\mathbf{X i Y i}$ & $\mathbf{X i}^{\mathbf{2}}$ \\
\hline $0,21 \times 10^{-5}$ & $1,67 \times 10^{7}$ & 35,07 & $0,0441 \times 10^{-1}$ \\
$0,19 \times 10^{-5}$ & $2,50 \times 10^{7}$ & 47,50 & $0,0361 \times 10^{-1}$ \\
$0,10 \times 10^{-5}$ & $5,94 \times 10^{7}$ & 59,40 & $0,01 \times 10^{-1}$ \\
$0,35 \times 10^{-5}$ & $1,98 \times 10^{7}$ & 69,30 & $0,1225 \times 10^{-1}$ \\
$0,31 \times 10^{-5}$ & $2,68 \times 10^{7}$ & 83,08 & $0,0961 \times 10^{-1}$ \\
$1,33 \times 10^{-5}$ & $0,68 \times 10^{7}$ & 90,44 & $1,7689 \times 10^{-1}$ \\
\hline
\end{tabular}

Function $\mathrm{F}(\mathrm{L})=\mathrm{F}(\mathrm{FA})=\left(\left[\mathrm{Cu}(\mathrm{II})_{\text {total }}\right]-\left[\mathrm{Cu}(\mathrm{II})_{\text {free }}\right]\right) /\left(\left[\mathrm{Cu}(\mathrm{II})_{\text {free }}\right]\left[\mathrm{FA}_{\text {free }}\right]\right)=\beta_{1}+\beta_{2}\left[\mathrm{FA}_{\text {free }}\right]$

where $\left[\mathrm{FA}_{\text {free }}\right]=\left[\mathrm{FA}_{\text {total }}\right]-[\mathrm{CuFA}]=\left[\mathrm{FA}_{\text {tota }} 1-[\mathrm{CuFA}]=\left[\mathrm{FA}_{\text {total }}\right]-\left(\left[\mathrm{Cu}(\mathrm{II})_{\text {total }}\right]-\left[\mathrm{Cu}(\mathrm{II})_{\text {free }}\right]\right)\right.$

When $\left[\mathrm{FA}_{\text {free }}\right]$ aspires to zero, $\beta$ could be found by the graphical method. The section which is cut on the ordinate by the straight line built in coordinates $\mathrm{F}(\mathrm{FA})-\left[\mathrm{FA}_{\text {free }}\right]$ equals to the stability constant. The value of $\beta$ was calculated by the square method.

$$
\begin{aligned}
& \beta=\left(\Sigma \mathrm{y}_{\mathrm{i}}-\mathrm{a} \Sigma \mathrm{x}_{\mathrm{i}}\right) / \mathrm{n} \\
& \text { where } \mathrm{a}=\left(\mathrm{n} \Sigma \mathrm{x}_{\mathrm{i}} \mathrm{y}_{\mathrm{i}}-\Sigma \mathrm{x}_{\mathrm{i}} \Sigma \mathrm{y}_{\mathrm{i}}\right) /\left(\mathrm{n} \Sigma \mathrm{x}_{\mathrm{i}}^{2}-\left(\Sigma \mathrm{x}_{\mathrm{i}}\right)^{2}\right) \\
& \mathrm{x}_{\mathrm{i}}=\left[\mathrm{FA}_{\text {free }}\right] \text { and } \mathrm{y}_{\mathrm{i}}=\mathrm{F}(\mathrm{FA}) \\
& \beta=2.25 \times 10^{7}
\end{aligned}
$$

\section{Conclusion}

It was shown that, during complex formation process, an associate of $\mathrm{FA}$, which $\mathrm{Mw}$ at $\mathrm{pH}=9$ equals to 7610 divides and every $1 / 4$ part of this associate inculcates into copper's inner coordination sphere, as an integral ligand. It was established, that in the $\mathrm{Cu}(\mathrm{OH})_{2}$ (solid)- $\mathrm{Cu}(\mathrm{II})$ (solution)-FA- $\mathrm{H}_{2} \mathrm{O}$ system at $\mathrm{pH}=9.0$, dominates copper fulvate complex with the structure $1: 1$, which $\beta=2.25 \times 10^{7}$.

\section{Acknowledgments}

The work was done by supporting the World Federation of Scientists and the World Laboratory. 


\section{References}

[1] Calin D, Cesar H, Josep G, Josep LG, Francesc M, Sandrine M, Jaume P,Carlos RC, Jose S. Effective affinity distribution for the binding of metal ions to a generic fulvic acid in natural waters. Environ Sci Technol. 2009; 43: 7184-7191.

[2] Jacques B, Herman P VL, Raewyn MT. Chemodynamics of Soft Nanoparticulate Complexes: Cu(II) and Ni(II) Complexes with Fulvic acids and Aquatic Humic Acids. Environ Sci Technol. 2012; 46:10487-10498.

[3] Hirata S. Stability constants for the complexes of transition-metal ions with fulvic and humic acids in sediments measured by gel-filtration. Talanta. 1981; 28:809-815.

[4] Taishi K, Hirotake M, Takayuki S, Ikuji T, Hatsumi Y. Determination of apparent formationconstants of Eu(III) with humic Substances by ion selective liquid membrane electrode. American Journal of Analytical Chemistry. 2012; 3:462-469.

[5] James HE. Heterogeneity as a concept in the inter-pretation of metal-ion binding by humic substances - the binding of zinc by an aquatic fulvic acid. Anal Chim Acta. 1992; 267:39-45.

[6] Morris S, S.I.M. Skinner. Organo-metallic interactions in soils: 5. stability constants of $\mathrm{Cu}++-, \mathrm{Fe}++-$, and $\mathrm{Zn++-}$ fulvic acid complexes. Soil Sci. 1966;102:361-365.

[7] Alexandre C B, Matheus P. F, Jerusa S G, Teodorico C. R. Marcello G T, Interactions fulvate-metal $\left(\mathrm{Zn}^{2+}, \mathrm{Cu}^{2+}\right.$ and $\mathrm{Fe}^{2+)}$ theoretical investigation of thermodynamic, structural and spectroscopic properties. Biometals. 2016; 29:275285.

[8] Akira K, Takashi O, N.Sato, Osamu T. Simplified modeling of the complexation of humic substance for equilibrium calculations. J Nucl Sci Technol. 2010; 4:71044-1054.

[9] Takumi K, Akira K, Yuichi N, Budi S, Osama T, Kouichi T, Hirofumi Y. Modeling of the complex formation of metal ions with humic acids. Radiochim Acta. 2004; 92:559-565.

[10] Galina MV. Migration forms of fulvic acids and metals in natural waters. Dissertation. Vernadsky Institute of Geochemistry and Analytical Chemistry of Russian Academy of Sciences, 1994.

[11] Ricardo Bicca de A, Teodorico de CR, Elaine E F da C, Aida E. Differential complexation between $\mathrm{Zn}^{2+}$ and Cd ${ }^{2+}$ with fulvic acid: a computational chemistry study. Water Air Soil Poll 2007;183:467-472.

[12] Jiang $\mathrm{H}$, Changwei L, Jinghua W, Boyi Z. Binding characteristics of $\mathrm{Pb}^{2+}$ to natural fulvic Acids extracted from the sediments in ake Wuliangsuhai, inner Mongolia plateau, P.R. China. Environmental Earth Sciences. 2016;75:768-779.

[13] Ya.S.Ivanechko, Peter L, Rostyslav L, Vladislav Z. Influence of the component composition of organic matter on relationship between dissolved forms of metals in the surface waters. Hydrobiological Journal. 2013;49:91-108.

[14] Giorgi M, Tamar M. Method of Calculation of Stability Constants of Fulvic Complexes on the Example of Copper. Journal of Chemistry and Chemical Engineering. 2014;8:108-111.

[15] Giorgi M, Robert R. Cloud-point preconcentration of fulvic and humic acids. Talanta. 1999; 48: 409-413.

[16] Giorgi M, Tamar M, Guram S. New Version of Calculation of Stability Constant of Metal-fulvate Complexes on the Example of Zinc Fulvate. International Journal of Environmental Science and Technology. 2018; 15:2165-2168.

[17] M.T. Beck and I. Nagypal. Chemistry of complex equilibria. Chichester, Horwood, New York,1990. 